\title{
Irigasi Kolon sebagai Pengganti Kolostomi pada Pembedahan Satu Tahap Penyakit Hirschsprung
}

\section{Colon Irrigation as Colostomy Replacement on Hirschsprung Disease Surgery}

\author{
Lulik Inggarwati, Bambang Triambodo ${ }^{2}$ \\ ${ }^{1}$ Laboratorium Ilmu Bedah Rumah Sakit Umum Dr. Saiful Anwar Malang \\ ${ }^{2}$ Laboratorium Ilmu Bedah Anak Rumah Sakit Bhayangkara Makasar
}

\begin{abstract}
ABSTRAK
Pada pasien dengan penyakit Hirschprung dengan stasis fecal harus di-dekompresi dahulu sebelum dilakukan penanganan definitive untuk menghindari enterokolitis. Ada dua macam modalitas dekompresi yaitu irigasi kolon dan kolostostomi (stoma). Pembedahan definitive dapat dilakukan dalam satu tahap atau dua tahap dan tidak terdapat perbedaan hasil luaran. Penelitian ini bertujuan membandingkan diameter kolon dan proporsi diameter kolon proksimal dan distal antara irigasi kolon (satu tahap pembedahan) dan kolostomi (dua tahap pembedahan). Uji klinis dilakukan pada 18 pasien yang dibagi secara acak dalam dua kelompok yaitu irigasi kolon (satu tahap pembedahan) dan kolostomi (dua tahap pembedahan). Tidak terdapat perbedaan bermakna dalam diameter kolon antara irigasi kolon (satu tahap pembedahan) dan kolostomi (dua tahap pembedahan). Pembedahan satu tahap atau dua tahap mempunyai luaran yang sama dalam hal proporsi diameter kolon.
\end{abstract}

Kata Kunci: Irigasi kolon, kolostomi, prosedur Duhamel

\begin{abstract}
In Hirschsprung disease patient with faecal stasis should be decompressed before definitive treatment to avoid enterocolitis. There are two decompression modalities, which are colon irrigation and colostomy (stoma). Definitive surgery can be performed with one step or two steps with no different outcome. This study was aimed to compare the differences of one step and two step surgery in term of colon width, proportion of colon proximal and distal width. A randomized clinical trial was performed in 18 patient randomized in two groups one with colon irrigation (one step of surgery) and the other group as a control with colostomy (two steps of surgery). There are no significant differences of the colon width between one step or two steps surgery $(p=0,406$ and $p=0,694)$. One step or two steps of surgery in Hirschsprung disease without enterocolitis have the same outcome in proportion of colon width.
\end{abstract}

Keywords : Colon irrigation, colostomy, Duhamel's procedure

Jurnal Kedokteran Brawijaya, Vol. 26, No.2, Agustus 2010; Korespondensi: Lulik Inggarwati. Laboratorium Ilmu Bedah, Rumah Sakit Umum Dr. Saiful Anwar Malang, Jl. Jaksa Agung Suprapto No.2 Malang Tel. (0341) 362101-362102 Email: ell_ing@yahoo.co.id 


\section{PENDAHULUAN}

Penyakit Hirschsprung adalah kelainan bawaan berupa terdapatnya segmen aganglion pada usus dari anus ke arah proksimal. Insiden penyakit Hirschsprung ini sebesar 1: 5.000-12.000 kelahiran hidup dan terdapat pada semua ras atau etnik. Diagnosis penyakit Hirschsprung secara cepat dan tepat sangat diperlukan karena salah satu komplikasi dari penyakit Hirschsprung adalah enterokolitis yang dapat mengakibatkan kematian. Hal ini terdapat pada 12-58\% kasus penyakit Hirschsprung (1-4).

Pada penderita Hirschsprung yang mengalami stasis feses harus segera dilakukan suatu tindakan untuk mencegah terjadinya enterokolitis. Tindakan yang dimaksud pada prinsipnya adalah mengurangi akumulasi masa feses dalam saluran pencernaan. Tindakan tersebut bertujuan mengurangi dilatasi atau diameter lumen usus proksimal dari segmen aganglion, yang dilakukan dengan cara nonbedah berupa irigasi kolon maupun dengan cara bedah yaitu kolostomi, sebelum dilakukan pembedahan definitive $(4,5)$. Kelebihan irigasi kolon dibanding kolostomi terletak pada fakta bahwa irigasi kolon merupakan cara non-bedah sehingga irigasi kolon dapat dilakukan oleh tenaga medis di wilayah yang tidak terdapat ahli bedah untuk kemudian diajarkan kepada keluarga pasien agar dilakukan di rumah, sambil menunggu pasien khususnya bayi bertambah umur dan beratnya untuk kelayakan operasi. Irigasi kolon merupakan metode profilaksis dan perawatan enterokolitis yang paling tepat. Hal tersebut telah dibuktikan dari laporan hasil penelitian di beberapa Negara. Beberapa kerugian dilakukannya kolostomi yaitu merupakan tindakan invasif bedah dengan pembuatan stoma, menimbulkan jaringan parut paska-kolostomi, rawat inap pasien lebih lama, biaya yang dikeluarkan semakin banyak, perawatan yang lebih sulit, serta kemungkinan terjadinya penyulit diantaranya prolap, stenosis, retraksi, hernia para stoma, dermatitis kontak dan invaginasi $(2,3)$.

Pembedahan sebagai terapi definitif pada penyakit Hirschsprung mempunyai tingkat keberhasilan lebih dari $90 \%$ kasus. Dalam pelaksanaannya dapat dipilih pembedahan satu tahap maupun dua tahap sesuai dengan indikasi dan indikasi kontra. Pembedahan satu tahap adalah dilakukan irigasi kolon terlebih dahulu sebelum pembedahan definitif (prosedur Duhamel). Pada pembedahan dua tahap dilakukan pembuatan stoma/ kolostomi dahulu sebelum pembedahan definitif. Indikasi pembedahan satu tahap pada penyakit Hirschsprung dilaksanakan pada penderita neonatus tanpa penyulit enterokolitis dan tidak terlambat terdiagnosa $(1,5,6)$.

Pada beberapa penelitian disebutkan bahwa tindakan bedah primary pull-through (satu tahap) hasil akhirnya tidak jauh berbeda daripada tindakan pembedahan dengan dua tahap. Penelitian di Perancis menyebutkan bahwa dari 35 pasien di bawah 3 bulan yang dioperasi satu tahap tanpa kolostomi, 27 menunjukkan hasil yang memuaskan (6). Di Indonesia belum ada data evaluasi keberhasilan pembedahan definitif satu tahap dibandingkan dua tahap. Penelitian eksperimental klinis ini bertujuan untuk membuktikan ada tidaknya perbedaan diameter lumen kolon setelah perlakuan irigasi kolon dibandingkan kolostomi pada pembedahan definitif Hirschsprung tanpa penyulit.

\section{METODE}

Penelitian ini dilakukan dengan desain randomized clinical trial dengan populasi terjangkau neonatus dengan penyakit Hirschsprung tanpa penyulit yang dirawat di Bangsal bedah anak RSSA Malang periode September 2005-2006. Jumlah keseluruhan subjek yang diperlukan adalah 18. Terdiri dari neonatus usia 2 sampai 30 hari, lakilaki 15 orang dan perempuan 3 orang. Subjek dibagi dalam 2 perlakuan masing-masing 9 subjek dalam kelompok satu tahap dalam kelompok dua tahap. Kriteria yang sesuai dengan protocol penelitian adalah neonatus dengan penyakit Hirschsprung tanpa penyulit enterokolitis, dan telah dilakukan irigasi kolon atau kolostomi sekitar 3-4 bulan secara efektif.

Neonatus dengan penyakit Hirschsprung tanpa penyulit enterokolitis diberi perlakuan irigasi kolon pada kelompok pertama dan kolostomi pada kelompok kedua sebelum dilakukan pembedahan definitif dengan teknik Duhamel. Penelitian ini tidak menimbulkan bahaya atau kerugian bagi pasien karena perlakuan irigasi kolon dengan cara yang benar jauh lebih aman dibandingkan tindakan invasif dengan kolostomi, disamping itu irigasi kolon telah diterapkan di beberapa bidang ilmu sebagai salah satu tindakan preparasi usus. Dalam pelaksanaannya telah mendapatkan persetujuan dari orangtua/keluarga terdekat penderita (informed consent) dan mendapat persetujuan dari komite etik penelitian (ethical clearance)

Variabel yang diukur adalah diameter lumen usus yang diukur dengan cara magnifikasi pada kolon in loop, usus proksimal dan distal; pembesaran lumen usus dan keseuaian lumen usus. Perbedaan pada dua kelompok diuji dengan uji t-test tidak berpasangan menggunakan SPSS versi 12

\section{HASIL}

Perbedaan efek dua teknik pemedahan yang berbeda pada penelitian ini dikaji dari diameter, pembesaran dan kesesuaian lumen usus. Dari pemeriksaan kolon in loop dapat diukur diameter awal lumen usus subjek penelitian yang datang pada periode neonatus (sampai usia 1 bulan). Pengukurannya dengan cara magnifikasi. Tabel 1 menggambarkan bahwa diameter awal lumen usus pada subjek penelitian dengan metode satu tahap $(17,44 \pm$ $2,068)$ dibandingkan dengan dua tahap $(16,89 \pm 2,088)$ tidak ada perbedaan yang bermakna secara statistik ( $p$ value $=0,579$ ). Perbandingan diameter lumen usus proksimal yang diukur saat pembedahan definitif satu tahap dan pembedahan definitif dua tahap, secara statistik tidak didapatkan perbedaan yang bermakna ( $\mathrm{p}$ value $=$ $0,881)$, demikian juga perbandingan diameter lumen usus distal $(p$ value $=0,741)$.

Tabel 1. Perbandingan diameter lumen usus

\begin{tabular}{cccc}
\hline Pengukuran & Group & $\begin{array}{c}\text { Mean } \pm \text { SD } \\
\text { (satuan dalam } \mathrm{mm} \text { ) }\end{array}$ & p value \\
\hline Diameter awal & 1 tahap & $17,44 \pm 2,068$ & 0,579 \\
& 2 tahap & $16,89 \pm 2,088$ & \\
Usus proksimal & 1 tahap & $24,67 \pm 1,000$ & 0,881 \\
& 2 tahap & $24,56 \pm 1,944$ & \\
Usus distal & 1 tahap & $22,00 \pm 1,118$ & \\
\hline
\end{tabular}

Disamping diameter lumen usus, dilakukan pengukuran pembesaran lumen usus. Kedua kelompok penilitian mendapatkan perlakuan dekompresi (kolostomi atau irigasi) selama 3-4 bulan. Perubahan besar diameter awal 
lumen usus (kolon in loop) sampai pada saat dilakukan pembedahan definitif satu tahap (7.22 sd 1.39) atau dua tahap (7.67 sd 0.7) bila dibandingkan tidak didapatkan perbedaan yang bermakna ( $p$ value $=0,406$ ). Kesesuaian lumen usus proksimal dan distal pada perlakuan satu tahap (2.67sd 0.5) dan dua tahap (2.78 sd 0.7) tidak menunjukkan perbedaan bermakna $(p=0.69)$.

Tabel 2. Perbandingan pembesaran dan kesesuaian diameter lumen usus

\begin{tabular}{lccc}
\hline \multicolumn{1}{c}{ Variabel } & Group & $\begin{array}{c}\text { Mean } \pm \text { SD } \\
\text { (satuan dalam mm) }\end{array}$ & P value \\
\hline $\begin{array}{l}\text { Pembesaran lumen usus } \\
\text { (kolon in loop-usus prox) }\end{array}$ & 1 tahap & $7,22 \pm 1,394$ & \\
& tahap & $7,67 \pm 0,707$ & 0,406 \\
$\begin{array}{l}\text { Kesesuaian lumen usus } \\
\text { (usus prox:distal) }\end{array}$ & 2 tahap & $2,67 \pm 0,500$ & \\
\hline
\end{tabular}

\section{PEMBAHASAN}

Operasi sebagai terapi definitif pada penyakit Hirschsprung mempunyai tingkat keberhasilan lebih dari $90 \%$ kasus. Dalam pelaksanaannya dapat dipilih metode satu tahap atau dua tahap sesuai indikasi dan indikasi kontraindikasi $(5,7)$. Dari analisis statistik hasil penelitian dengan menggunakan $t$-test untuk mengetahui perbandingan perubahan besar serta kesesuaian lumen usus pada pembedahan definitif Hirschsprung baik dengan metode satu tahap maupun dua tahap didapatkan pembesaran diameter lumen usus dari periode neonatus sampai saat dilakukan pembedahan definitif (diameter lumen usus proksimal) tidak memberikan perbedaan yang bermakna. Meskipun demikian metode satu tahap mempunyai kecenderungan nilai lebih kecil (mean \pm SD $=$ $7,22 \pm 1,394)$. Semakin kecil perubahan besar lumen usus mencerminkan semakin baiknya tindakan dekompresi yang dilakukan. Faktor-faktor yang berperan dalam keberhasilan irigasi kolon adalah ketaatan dan ketepatan cara irigasi sedangkan pada perlakuan dengan stoma

\section{DAFTAR PUSTAKA}

1. Kartono D. Penyakit Hirschsprung. Cetakan I. Jakarta: Sagung Seto; 2004; hal. 1-81.

2. Ashcraft KW. Pediatric Surgery. Third edition. Philadelphia: W.B. Saunders Company; 2000: p. 453468.

3. Minford JL, Rama A, Turrnock RR, et al. Comparison of Functional Outcomes of Duhamel and Transanal Endorectal Coloanal Anastomosis for Hirschsprung's Disease. Journal of Pediatric Surgery. 2004; 39(2): 161-165; discussion 161-165.

4. O'Neill J, Grosfeld J, and Fonkalsrud E. Principles of Pediatric Surgery. 2nd edition. Philadelphia: Elsivier; 2003; p. 631-649.

5. Neville H. Hirschprung Disease. (Online) 2003. http://www.emedicine.com/ped/topic 1010.htm

6. Honchar VV. The Prevention and Treatment of Enterocolitis in Children with Hirschsprung's Disease. Likars'ka Sparva. 2000; 2: 69-72.

7. Lee SL. Hirschprung Disease. (Online) 2003. (kolostomi) ditentukan dari teknik pembuatan dan perawatan kolostomi $(4,5,8)$.

Kesesuaian (proposionalitas) antara lumen usus proksimal dan distal yang akan dilakukan anastomose juga mencerminkan keberhasilan tindakan dekompresi dengan irigasi kolon maupun kolostomi (9). Pada penelitian ini baik metode satu tahap maupun dua tahap memberikan gambaran tidak ada perbedaan yang bermakna terhadap kesesuaian lumen usus. Meskipun demikian metode satu tahap dengan menggunakan irigasi kolon mempunyai kecenderungan nilai lebih kecil (mean \pm $\mathrm{SD}=2,67 \pm 1,500)$.

Honchar menyebutkan bahwa metode yang paling efektif untuk profilaksis dan penanganan enterokolitis adalah dengan dekompresi dengan teknik irigasi kolon. Dilihat dari aspek klinis terhadap penderita dan keluarganya, pembedahan definitif satu tahap mempunyai kelebihan dibandingkan dua tahap dalam hal lebih sedikit tindakan bedah yang dilakukan, tidak ada komplikasi yang timbul seperti pada pembuatan kolostomi / stoma. Disamping itu pada pembedahan satu tahap perawatan pra bedah lebih mudah, biaya yang dikeluarkan semakin sedikit, memperpendek masa rawat inap pasien, keluarga dan penderita terhindar dari beban psikologis akibat pembuatan kolostomi / stoma $(11,12)$.

Dari Tabel 2 terlihat bahwa perbandingan metode satu tahap dan dua tahap secara statistik tidak ada perbedaan yang bermakna dalam hal pembesaran diameter lumen usus maupun kesesuaian diameter lumen usus. Dari aspek klinis metode satu tahap lebih banyak keuntungannya dibandingkan dua tahap. Hasil penelitian ini membuktikan pembedahan satu tahap dibandingkan pembedahan dua tahap pada neonatus dengan penyakit Hirschsprung tanpa penyulit enterokolitis memberikan hasil yang sama dalam hal kesesuaian dan pembesaran diameter lumen usus. Dari aspek klinis metode satu tahap lebih menguntungkan dibandingkan dengan dua tahap, sehingga metode satu tahap dengan irigasi kolon dapat menggantikan metode dua tahap pada penatalaksanaan neonatus dengan Hirschsprung tanpa penyulit.

http://www.emedicine.com/ped/topic 1016.htm

8. Covau AG and Tetelbaum DH. Recent Advances in the Management of Hirschsprung's Disease. The American Journal of Surgery. 2000; 180(5): 382-387.

9. Shankar KR, Losty PD, Lamont GL, et al. Transanal endorectal coloanal surgery for Hirschsprung's disease: experience in two centers. Journal of Pediatric Surgery. 2000; 35(8): 1209-1213.

10. Marty TL, Seo T, Sullivan JJ, Matlak ME, Black RE, and Johnson DG. Rectal Irrigations for the Prevention of Postoperative Enterocolitis in Hirschsprung's Disease. Journal of Pediatric Surgery. 1995; 30(5): 652-654.

11. Wester T and Rintala RJ. Early Outcome of Transanal Endorectal Pull-through With a Short Muscle Cuff During the Neonatal Period. Journal of Pediatric Surgery. 2004; 39(2): 157-160; discussion 157-160.

12. Antao B, Radhwan T, Samuel M, and Kiely E. Shortpouch and Low-anastomosis Duhamel Procedure Results in Better Fecal Control and Normal Defecation Pattern. Diseases of the Colon \& Rectum. 2005; 48(9): 1791-1796 